\title{
Psychometric properties of the German-language questionnaire for urinary incontinence diagnosis (QUID) in women with urinary incontinence
}

\author{
Florian Brandt ${ }^{1,2}$ [D $\cdot$ Erich-Franz Solomayer ${ }^{1} \cdot$ Panagiotis Sklavounos $^{1}$
}

Received: 29 January 2021 / Accepted: 27 July 2021 / Published online: 6 August 2021

(c) The Author(s) 2021

\begin{abstract}
Purpose The aim of this study was to translate the questionnaire for urinary incontinence diagnosis (QUID) into German and to assess its psychometric properties in German-speaking women with urinary incontinence (UI). The QUID contains two subscales to measure symptom severity of stress urinary incontinence (SUI) and urge urinary incontinence (UUI) and to distinguish between both forms.

Methods A total of 161 women with UI completed the QUID and the King's Health Questionnaire (KHQ), each in the German version. To examine construct validity Spearman's correlation coefficients between both questionnaires were computed. Furthermore, the internal consistency (Cronbach's alpha) of the QUID and its criterion validity were examined. Looking at criterion validity, sensitivity, specificity, ROC curves, and Youden-indexes were computed for both subscales.

Results The QUID showed good construct validity by strong correlations with related domains of the KHQ. Cronbach's alpha values were good for both subscales of the QUID (SUI-subscale: 0.76; UUI-subscale: 0.86). Sensitivity and specificity were $83 \%$ (95\% CI, 0.72-0.9) and 45\% (95\% CI, 0.25-0.67) for the SUI-subscale and 83\% (95\% CI, 0.7-0.91) and 56\% ( $95 \%$ CI, 0.4-0.72) for the UUI-subscale. Youden-index was 0.28 for the SUI-subscale and 0.39 for the UUI-subscale at the given cut-off values.

Conclusion Psychometric properties of the German-language QUID are principally good and support its use in the Germanspeaking area. However, the modest specificity when distinguishing between SUI and UUI should be taken into account. Trial registration number: DRKS00018777 (date of registration: 16-January-2020).
\end{abstract}

Keywords Diagnostic accuracy $\cdot$ Patient reported outcome measures $\cdot$ Stress urinary incontinence $\cdot$ Sensitivity and specificity $\cdot$ Urge urinary incontinence $\cdot$ Validation study

\section{Introduction}

Urinary incontinence (UI) is a ubiquitous issue in gynaecologic practice and puts a lot of distress on patients who are affected [1]. The most common forms are stress urinary incontinence (SUI), urge urinary incontinence (UUI), or related mixed forms (MUI) [2]. Since SUI and UUI may require a different treatment, it is essential to distinguish

Florian Brandt

florian.brandt@uni-saarland.de

1 Clinic for Gynecology, Obstetrics and Reproductive Medicine, Saarland University Hospital and Medical Faculty of Saarland University, Homburg, Germany

2 Saarland University, Saarbrücken, Germany between both forms [1-3]. A simple and feasible method for this purpose is the Questionnaire for Urinary Incontinence Diagnosis (QUID). It is a patient-reported outcome measure (PROM) which consists of two subscales to identify SUI and/ore UUI if existing [4]. Each subscale consists of three items to measure the symptom severity of the respective type of UI. Values of each item range from zero 'none of the time' to five 'all of the time' [4]. Adding the values gives a score (0-15) for each subscale [4]. Values equal to or greater than four in the SUI-subscale indicate SUI, while values equal to or greater than six in the UUI-subscale indicate UUI $[4,5]$. The original English version is recommended for use as basic diagnostic tool to distinguish between SUI, UUI, and MUI in urogynecologic practice as well as to measure patient reported outcomes within respective clinical trials [4, 
5]. Furthermore, it enables women to assess their UI type on their own [6].

However, since every language area has its distinctions, it is necessary to re-validate patient questionnaires if translated what means to accurately check their psychometric properties. In this regard the following quality criteria regularly are of interest: reliability, validity, and, in case of patient questionnaires like the QUID, which are supposed to discriminate between certain conditions, diagnostic accuracy $[7,8]$. Reliability describes the replicability of the results of a measuring instrument. It indicates the extent to which several measurements that were carried out under the same conditions agree with each other. Reliability can be estimated using various methods. With regard to patient questionnaires internal consistency regularly is examined. Internal consistency indicates the extent to which several items that are supposed to measure the same dimension within a multi-item scale are related to each other. Validity describes the accuracy to which the condition that is supposed to be measured actually is measured. Forms of validity that play a special role within psychometric assessment of questionnaires are construct and criterion validity. Construct validity is usually verified by comparing the questionnaire to a similar questionnaire which has already been proven, while criterion validity examines the extent to which the questionnaire's results agree with external criteria like physician's diagnosis. Diagnostic accuracy relates to the ability of the questionnaire to discriminate between certain conditions (e.g. two forms of UI).

While the QUID had been part of respective studies performed in women speaking Spanish [9], Chinese [10], Thai [11], or Persian [12], its applicability in German-speaking women has not yet been checked. Therefore, the aim of this study was to translate the QUID into German, evaluate its psychometric properties in women with UI, and support its use in the German-speaking area based on scientific evidence.

\section{Materials and methods}

\section{Data collection}

An online survey was mailed to 3500 women in Germany via a German health insurance company in August 2020. Contacted women were randomly selected out of women $\geq 18$ years of age. Within the mailing all women were informed about the study's aims and about voluntariness and anonymity of participation. Of course it was possible to forward the survey link to other people of the personal environment. All participants had to fully complete the survey, had to be female, had to suffer from UI, and had to be $\geq 18$ years old to be included in this study (inclusion criteria). To prevent a high dropout rate, which is higher within online surveys anyway, the survey was done without a comprehensive inquiry of characteristics going beyond gender, few sociodemographics, and type of incontinence. Consequently there were no specific exclusion criteria. However, this was acceptable since no treatment was investigated in the course of this study and, therefore, no confounding variables in terms of any treatment effect had to be controlled. Informed consent was assumed by taking part and submitting the survey after completion.

\section{Measurements}

Initially, some general information concerning age, size, weight, gender, existence, and duration of UI was requested. Diagnosis data were retrieved by asking every participant if the complaint has already been diagnosed by a physician and if 'yes', what kind of UI (SUI, UUI, MUI) was diagnosed if sufficiently well-known. UI diagnosis regularly includes a comprehensive anamnesis of symptoms, micturition, and medical history as well as a physical examination to assess urethral support, descensus of pelvic organs, and stress test. If UI is not adequately clarified afterwards, patients undergo additional testing, including voiding diaries, pad tests, urinalysis, ultrasound, or urodynamic tests. Retrieving diagnosis data made it possible to examine criterion validity of the QUID by comparing its results with the reported physicians' diagnoses as referenceable 'gold standard' $[4,6]$. In the main part of the survey the QUID and the King's Health Questionnaire (KHQ) were filled in. The QUID was described in the introduction. It was translated into German based on the ISPOR principles of good practice in the cross-cultural adaption process for patient-reported outcome measures [13] passing through the following steps:

1. Forward translation: Initial translation of the QUID from English to German was performed in a team of German native speakers. All members were fluent in English. There were no substantial differences between the translations of the team members. Therefore it was no issue to obtain a single concerted version.

2. Back translation: The German version was submitted to another team of English native speakers for back translation. All members were fluent in German and had no prior knowledge of the measure. Again there were no substantial differences both between the translations of the team members and between their translations and the original version. Therefore the concerted version of step 1 seemed to be applicable.

3. Testing and revision: Finally, the concerted version and alternative wording was discussed with medical practitioners. The obtained version was handed out to a small group in order to check understandability and interpreta- 
tion. No problems occurred and the German-language QUID was finalized.

Permission to use the QUID within this study was granted by its developers. The translated German-language version of the QUID can be found in the "Appendix".

The KHQ was used as a reference tool to check the construct validity of the QUID. The KHQ is a disease-specific quality of life (QoL) measure within the scope of UI [14]. It has already been validated for many languages $[15,16]$ including German [17, 18]. Moreover, it is recommended for use both in practice and research by the International Consultation on Incontinence (ICI) with the highest recommendation rate [19]. It contains seven multi-item domains: Role Limitations, Physical Limitations, Social Limitations, Personal Relationship, Emotional Problems, Sleep and Energy Disturbances, Severity Measures and two singleitem domains: General health Perception and Incontinence Impact $[14,20]$. Additionally, the current version includes a symptom severity scale with ten items assessing the presence and relative severity of incontinence symptoms, including one item to measure 'urine leakage at physical activity' [20]. Concerning the German version the first four items within the symptom severity scale capture symptoms of overactive bladder (OAB) [17, 18]. The possible score for each subscale ranges from zero (best health perception) to 100 (worst health perception) [14, 20]. Deviating from this, the individual results of the ten items within the Symptom Severity Scale are just added and can reach a total value of 0-30 (possible values are 0-3 at each Item) [20].

\section{Statistical analysis}

First, descriptive statistics (mean, standard deviation (SD)) were computed for sample characteristics. The values were grouped according to type of UI. Group differences were computed using Kruskal-Wallis test, a non-parametric alternative to one-way ANOVA [21]. Both questionnaires were then checked for normal distribution of their scores and descriptive statistics were computed for both questionnaires too. This allowed for checking the QUID for floor and ceiling effects (percentages of subjects with the lowest and the highest possible scores). To receive a first impression of the QUID's diagnostic accuracy, group differences regarding its scores were examined as follows: women with SUI vs. women without SUI and women with UUI vs. women without UUI. Hereto non-parametric Wilcoxon-Mann-Whitney test [22] was used.

Internal consistency was determined using Cronbach's alpha. Cronbach's alpha measures the extent to which the items of a subscale are related to one another (interrelatedness) [23]. It was computed for the QUID's subscales and the entire QUID. A value of $\geq 0.7$ was considered acceptable
[7]. Additionally, Spearman correlation coefficients between the responses of each individual item and the corresponding total score of the associated subscale ommitting that item were computed.

Construct validity is confirmed if there is strong correlation with a test which measures the same construct (convergent validity) and weak correlation with a test which measures another construct (discriminant validity). To test construct validity of the QUID its correlation with the KHQ was examined. Since its scores had non-normal distribution, Spearman's rho $\left(r_{\mathrm{s}}\right)$, a non-parametric correlation test, was used to compare the responses. Spearman's rho was computed both for the overall QUID and its subscales with each domain of the KHQ. Furthermore, correlations between the subscales of the QUID were computed. Values from 0.1 to 0.3 were considered weak, 0.3 to 0.5 moderate, and $\geq 0.5$ strong [24].

To examine criterion validity and diagnostic accuracy, sensitivity (SE) and specificity (SP), including 95\% confidence intervals, were calculated for each subscale using the reported physicians' diagnoses as reference value. In addition, we drew a ROC-curve (receiver operating characteristic curve) for each subscale. A ROC-curve is a graph showing the performance of a classification model at all classification thresholds meaning all possible cut-off scores. It plots the true positive rate ( $=$ sensitivity) at the ordinate and the false positive rate ( $=1-$ specificity) at the abscissa ( $x$-axis) of a two-dimensional graph [25]. In addition to this Youden's J (also called Youden's index) was calculated. Youden's J is a measure to determine which cut-off score is most qualified to distinguish between the two groups (non-SUI vs. SUI, respectively, non-UUI vs. UUI). It is calculated as follows: Youden's J = sensitivity + specificity -1 . The higher Youden's J, the higher the performance of the related cut-off score in terms of the combination of sensitivity and specificity [26]. Finally, the hit ratio for the overall QUID at the given cut-off scores was computed. At computation of the hit ratio a match with physician diagnosis in both subscales was counted as 'correct' $(=1)$, a match in just one subscale as 'partly correct' $(=0.5)$, and no match as 'wrong' $(=0)$.

The statistical analysis was performed using $R$, a free software environment for statistical computing and graphics.

\section{Sample size calculation}

To examine the interesting group differences between women with and without UUI, which were expected to be large [5], with a power $(1-\beta)$ of 0.8 and $\alpha=0.05$, a minimum sample size of 32 women with UUI and 24 women without UUI was required (computed with G*Power [27]; test: Wilcoxon-Mann-Whitney test (two groups); tails: two; effect size: 0.8 [24]; allocation ratio: 53/39 (based on current allocation)). To assess the interesting group differences 
between women with and without SUI, which were expected to be large too, with a power of 0.8 and $\alpha=0.05$, a minimum sample size of 56 women with SUI and 18 women without SUI was required (computed with G*Power [27]; test: Wilcoxon-Mann-Whitney test (two groups); tails: two; effect size: 0.8 [24]; allocation ratio: 70/22 (based on current allocation)).

To compute the interesting correlation coefficients between comparable measures, which were expected to be strong [5], with a power of 0.8 and $\alpha=0.05$, a minimum sample size of 26 was required (computed with $G^{*}$ Power [27]; test: linear bivariate regression, one group; tails: two; correlation: 0.5 [24]; SD (x): 30 [18]; SD (y): 3 [5]).

\section{Results}

\section{Study population}

Of the 3500 contacted women 246 (7\%) took part in the anonymous online survey carried out in August/September 2020. Thereof $161(65 \%)$ met the inclusion criteria and were included in this study. Meaning all of the included women fully completed the survey, were $\geq 18$ years old, and had UI, of which 92 (57\%) reported the type of UI diagnosed by a physician: 39 SUI (42\%), 22 UUI (24\%), and 31 MUI (34\%). In 69 participants the type of UI was not recorded because it wasn't sufficiently well known. Since respective data are necessary to consider sensitivity and specificity, only 92 of 161 women were included in this part. An overview of the sample characteristics can be found in Table 1. There were no significant differences between groups concerning age, weight, height, or BMI.

\section{Outcomes and internal correlations}

Shapiro-Wilk test of normality [28] showed that neither the scores of the QUID, nor of the KHQ were normally distributed ( $p<0.05$ in each case).

Table 2 shows the mean scores of the QUID and the KHQ according to type of UI and overall. Women with SUI had a significantly higher score in the SUI-subscale of the QUID $(\alpha \leq 0.05)$ while women with UUI had a significantly higher UUI-score $(\alpha \leq 0.01)$. The same applies to related domains of the KHQ. Overall, the mean scores were higher in women with UUI or MUI than in women with SUI. Only in the KHQ item 'Urine leakage at physical activity' as well as in the SUI-Subscale of the QUID mean scores were higher in women with SUI.

A maximum of $n=7$ (4\%) of participants' scores clustered to the bottom end (floor) and a maximum of $n=3(2 \%)$ to the top end (ceiling) of the QUID. The maximum at the bottom end occurred in the SUI-subscale while the maximum at the top end occurred in the UUI-subscale.

The internal correlations of the QUID are shown in Table 3. In addition to respective values in Table 3, Cronbach's alpha was 0.75 (95\% CI, 0.69-0.81) for the overall QUID.

\section{Correlations between QUID and KHQ}

Spearman's correlation coefficients and related $p$-values are shown in Table 4. The SUI-Subscale of the QUID was strongly correlated to the single item 'urine leakage at physical activity' $(p<0.01)$ and moderately correlated with the domains 'Incontinence impact', 'Role limitations', 'Physical limitations', 'Severity measures', and the 'Symptom severity scale' $(p<0.01)$. There were low correlations $(p<0.01)$ with 'Social limitations', 'Personal relationship', and 'Emotional problems' and no correlations with 'General health perception', 'Sleep and energy disturbances', and 'Overactive bladder'. The UUISubscale of the QUID significantly was correlated with every
Table 1 Sample characteristics $($ mean \pm SD or $n(\%)$ )

\begin{tabular}{llllll}
\hline & $\begin{array}{l}\text { SUI patients } \\
(n=39)\end{array}$ & $\begin{array}{l}\text { UUI patients } \\
(n=22)\end{array}$ & $\begin{array}{l}\text { MUI patients } \\
(n=31)\end{array}$ & $\begin{array}{l}p \text {-value } \\
(H \text {-test })\end{array}$ & $\begin{array}{l}\text { Overall } \\
(n=161)\end{array}$ \\
\hline Age (years) & $54.2 \pm 10.4$ & $53.1 \pm 12.2$ & $58.1 \pm 9.4$ & 0.229 & $56.2 \pm 10.2$ \\
Height $(\mathrm{cm})$ & $167.7 \pm 6.5$ & $166.7 \pm 7.1$ & $166.8 \pm 6.7$ & 0.494 & $167.6 \pm 6.5$ \\
Weight $(\mathrm{kg})$ & $82.7 \pm 17.9$ & $85.1 \pm 22.4$ & $85.9 \pm 21.9$ & 0.872 & $85.5 \pm 21.4$ \\
BMI & $29.5 \pm 6.7$ & $30.6 \pm 8.0$ & $30.9 \pm 8.0$ & 0.831 & $30.5 \pm 7.6$ \\
Duration of UI & & & & & \\
$<1$ year & $4(10 \%)$ & $4(18 \%)$ & $2(6 \%)$ & - & $19(12 \%)$ \\
$1-3$ years & $9(23 \%)$ & $11(50 \%)$ & $12(39 \%)$ & - & $65(40 \%)$ \\
$>3$ years & $26(67 \%)$ & $7(32 \%)$ & $17(55 \%)$ & - & $77(48 \%)$ \\
\hline
\end{tabular}

$B M I$ body mass index; $\mathrm{cm}$ centimeter; $\mathrm{kg}$ kilogram; $M U I$ mixed urinary incontinence; $n$ sample size; $S D$ standard deviation; SUI stress urinary incontinence; UI urinary incontinence; UUI urge urinary incontinence 
Table 2 KHQ and QUID scores (mean \pm SD)

\begin{tabular}{|c|c|c|c|c|c|c|}
\hline & $\begin{array}{l}\text { SUI patients } \\
(n=39)\end{array}$ & $\begin{array}{l}\text { UUI patients } \\
(n=22)\end{array}$ & $\begin{array}{l}\text { MUI patients } \\
(n=31)\end{array}$ & $\begin{array}{l}p \text {-value with vs. } \\
\text { without SUI }\end{array}$ & $\begin{array}{l}p \text {-value with vs. } \\
\text { without UUI }\end{array}$ & $\begin{array}{l}\text { Overall } \\
(n=161)\end{array}$ \\
\hline \multicolumn{7}{|l|}{ KHQ } \\
\hline General health perception & $34.6 \pm 27.3$ & $47.7 \pm 24.3$ & $46.0 \pm 25.9$ & 0.213 & 0.037 & $42.2 \pm 25.5$ \\
\hline Incontinence impact & $71.8 \pm 31.1$ & $83.3 \pm 22.4$ & $88.2 \pm 25.2$ & 0.816 & 0.023 & $71.9 \pm 30.0$ \\
\hline Role limitations & $54.2 \pm 30.8$ & $75.0 \pm 26.6$ & $77.9 \pm 26.3$ & 0.184 & $<0.01$ & $60.9 \pm 31.1$ \\
\hline Physical limitations & $48.7 \pm 26.9$ & $58.3 \pm 35.6$ & $72.0 \pm 28.7$ & 0.974 & $<0.01$ & $51.6 \pm 31.3$ \\
\hline Social limitations & $28.2 \pm 31.5$ & $32.5 \pm 33.6$ & $46.7 \pm 32.2$ & 0.668 & 0.071 & $30.2 \pm 31.8$ \\
\hline Personal relationship ${ }^{a}$ & $35.1 \pm 25.4$ & $51.3 \pm 25.0$ & $41.6 \pm 32.4$ & 0.125 & 0.134 & $36.4 \pm 28.2$ \\
\hline Emotional problems & $44.4 \pm 34.4$ & $60.1 \pm 31.7$ & $60.5 \pm 31.3$ & 0.331 & 0.030 & $44.4 \pm 33.1$ \\
\hline Sleep and energy disturbances & $30.7 \pm 29.5$ & $56.0 \pm 33.6$ & $57.5 \pm 33.9$ & 0.083 & $<0.01$ & $39.5 \pm 31.6$ \\
\hline Severity measures & $69.7 \pm 23.3$ & $72.7 \pm 18.4$ & $78.7 \pm 18.8$ & 0.629 & 0.227 & $70.5 \pm 21.9$ \\
\hline Overactive bladder $^{\mathrm{b}}$ & $42.8 \pm 29.8$ & $80.7 \pm 24.6$ & $79.8 \pm 23.5$ & $<0.01$ & $<0.01$ & $58.4 \pm 32.0$ \\
\hline Symptom severity scale & $11.6 \pm 6.1$ & $15.1 \pm 5.5$ & $15.3 \pm 5.6$ & 0.176 & $<0.01$ & $12.9 \pm 6.2$ \\
\hline Urine leakage at physical activity & $2.3 \pm 0.8$ & $1.5 \pm 1.2$ & $2.1 \pm 1.0$ & $<0.01$ & 0.049 & $2.1 \pm 1.0$ \\
\hline \multicolumn{7}{|l|}{ QUID } \\
\hline SUI-Subscale & $7.5 \pm 3.1$ & $5.1 \pm 4.5$ & $7.2 \pm 3.8$ & 0.014 & 0.099 & $6.4 \pm 3.8$ \\
\hline UUI-Subscale & $5.9 \pm 3.7$ & $8.4 \pm 3.2$ & $9.3 \pm 3.7$ & 0.249 & $<0.01$ & $7.0 \pm 3.8$ \\
\hline Overall & $13.4 \pm 5.2$ & $13.5 \pm 5.8$ & $16.4 \pm 5.8$ & 0.244 & 0.211 & $13.4 \pm 5.9$ \\
\hline
\end{tabular}

$K H Q$ King's Health Questionnaire; $n$ sample size; $Q U I D$ Questionnaire for Urinary Incontinence Diagnosis; $S D$ standard deviation; $S U I$ stress urinary incontinence; $U U I$ urge urinary incontinence

${ }^{a}$ Because of missing values $n=109$ in this domain (SUI patients: $n=28$; UUI patients: $n=13$; MUI patients: $n=22$ )

${ }^{\mathrm{b}}$ Because of missing values $n=158$ in this domain (SUI patients: $n=38$; UUI patients: $n=22$; MUI patients: $n=31$ )

Table 3 Internal correlations of the QUID

\begin{tabular}{llll}
\hline & $\begin{array}{l}\text { Corr. with SUI- } \\
\text { scale }^{\mathrm{a}}\end{array}$ & $\begin{array}{l}\text { Corr. with } \\
\text { UUI-scale }^{\mathrm{b}}\end{array}$ & Cronbach's alpha \\
\hline Item 1 & $0.57^{\mathrm{d}}$ & 0.04 & - \\
Item 2 & $0.63^{\mathrm{d}}$ & $0.36^{\mathrm{d}}$ & - \\
Item 3 & $0.55^{\mathrm{d}}$ & 0.11 & - \\
SUI-scale & $1.0^{\mathrm{d}}$ & $0.18^{\mathrm{c}}$ & $0.76(0.7-0.83)^{\mathrm{e}}$ \\
Item 4 & $0.21^{\mathrm{d}}$ & $0.7^{\mathrm{d}}$ & - \\
Item 5 & 0.15 & $0.75^{\mathrm{d}}$ & - \\
Item 6 & 0.13 & $0.74^{\mathrm{d}}$ & - \\
UUI-scale & $0.18^{\mathrm{c}}$ & $1.0^{\mathrm{d}}$ & $0.86(0.82-0.89)^{\mathrm{e}}$ \\
\hline
\end{tabular}

Corr. correlation; $n$ sample size; $P P$-value; $Q U I D$ Questionnaire for Urinary Incontinence Diagnosis; $S U I$ stress urinary incontinence; UUI urge urinary incontinence

atem 1-3: Spearman correlation between individual item response and the SUI-score omitting that item. Rest: Overall Spearman correlation

b Item 4-6: Spearman correlation between individual item response and the UUI-score omitting that item. Rest: Overall Spearman correlation

${ }^{\mathrm{c}} p<0.05$

${ }^{\mathrm{d}} p<0.01$

${ }^{\mathrm{e}} 95 \%$ confidence interval in brackets domain of the KHQ $(p<0.01)$ except 'urine leakage at physical activity'. There were low correlations with 'General health perception', moderate correlations with 'Social limitations', 'Personal relationship', and 'Emotional problems' and high correlations with the remaining domains. The overall QUID also correlated with every domain of the KHQ at a significance level of $\alpha \leq 0.01$ respectively $\alpha \leq 0.05$ (only for the domain 'General health perception'). There was a low correlation with 'General health perception' and moderate to high correlations with the remaining domains.

\section{Sensitivity, specificity, and ROC curves}

Sensitivity (SE) and Specificity (SP) were calculated both for the SUI- and the UUI-subscale of the QUID. Regarding the SUI-Subscale (given cut-off score $\geq 4$ ) the following results were obtained: $\mathrm{SE}=0.83(95 \% \mathrm{CI}, 0.72-0.9)$ and $\mathrm{SP}=0.45$ (95\% CI, 0.25-0.67). Corresponding results for the UUI-Subscale (given cut-off score $\geq 6$ ) were: $\mathrm{SE}=0.83$ (95\% CI, 0.7-0.91) and SP $=0.56$ (95\% CI, 0.4-0.72). The ROC-curves are shown in Fig. 1. The given classification threshold of the SUI-Subscale did not result in an optimum regarding Youden's J $(0.28$ for the given cut-off score $\geq 4)$. A cut-off score $\geq 6$ would result in Youden's $\mathrm{J}=0.33, \mathrm{SE}=0.69$ (95\% CI, 0.56-0.79), and SP $=0.64$ (95\% CI, 0.41-0.82). 
Table 4 Correlations between QUID and KHQ (Spearman's rho)

\begin{tabular}{llll}
\hline & QUID SUI score & QUID UUI score & QUID total score \\
\hline KHQ & & & \\
General health perception & 0.02 & $0.26^{\mathrm{b}}$ & $0.19^{\mathrm{a}}$ \\
Incontinence impact & $0.38^{\mathrm{b}}$ & $0.54^{\mathrm{b}}$ & $0.61^{\mathrm{b}}$ \\
Role limitations & $0.38^{\mathrm{b}}$ & $0.57^{\mathrm{b}}$ & $0.61^{\mathrm{b}}$ \\
Physical limitations & $0.4^{\mathrm{b}}$ & $>0.5^{\mathrm{b}}$ & $0.59^{\mathrm{b}}$ \\
Social limitations & $0.24^{\mathrm{b}}$ & $0.47^{\mathrm{b}}$ & $0.45^{\mathrm{b}}$ \\
Personal relationship & $0.27^{\mathrm{b}}$ & $0.31^{\mathrm{b}}$ & $0.4^{\mathrm{b}}$ \\
Emotional problems & $0.27^{\mathrm{b}}$ & $0.4^{\mathrm{b}}$ & $0.45^{\mathrm{b}}$ \\
Sleep and energy disturbances & 0.09 & $0.53^{\mathrm{b}}$ & $0.41^{\mathrm{b}}$ \\
Severity measures & $0.41^{\mathrm{b}}$ & $0.45^{\mathrm{b}}$ & $0.55^{\mathrm{b}}$ \\
Overactive bladder & 0.02 & $0.6^{\mathrm{b}}$ & $0.38^{\mathrm{b}}$ \\
Symptom severity scale & $>0.3^{\mathrm{b}}$ & $0.54^{\mathrm{b}}$ & $0.54^{\mathrm{b}}$ \\
Urine leakage at physical activity & $0.65^{\mathrm{b}}$ & 0.02 & $0.43^{\mathrm{b}}$ \\
\hline
\end{tabular}

$K H Q$ King's Health Questionnaire; $n$ sample size; $p$-value; $Q U I D$ Questionnaire for Urinary Incontinence Diagnosis; SUI stress urinary incontinence; UUI urge urinary incontinence

${ }^{\mathrm{a}} p<0.05$

${ }^{\mathrm{b}} p<0.01$

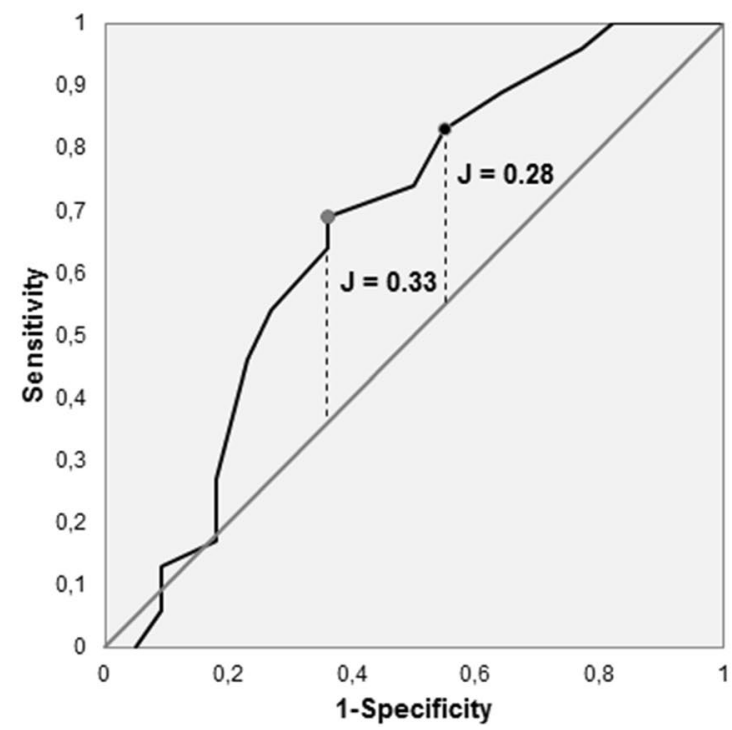

Fig. 1 ROC curves for the SUI-subscale (left) and the UUI-subscale (right). The ROC curves are delineated in black. The black points on the ROC curves represent the sensitivity/1-specificity-combinations for the given cut-off values. Related Youden's J is given too. Since the

The given cut-off score $\geq 6$ in the UUI-Subscale resulted in an optimum of Youden's J (0.39).

Hit ratio for the overall QUID was $73 \%$ at the given cutoff scores.

\section{Discussion}

The aim of this study was to assess the psychometric properties of the German-language QUID in women with UI. Required data were collected in 161 appropriate women which made it

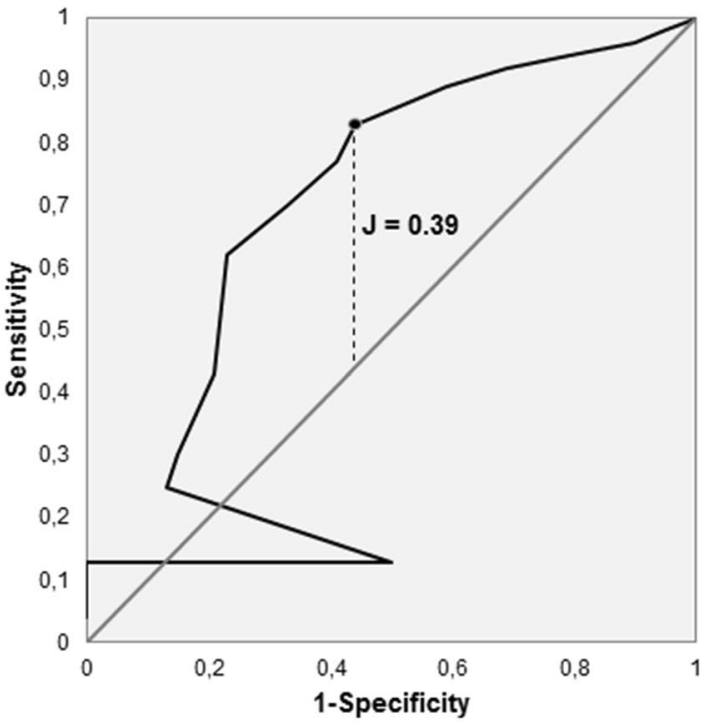

given cut-off value of the SUI-subscale $(\geq 4)$ didn't result in an optimum of Youden's J, the left grey point shows the sensitivity/1-specificity-combination where Youden's J reaches an optimum (cut-off value $\geq 6$ ). The diagonal represents decisions based purely on chance

possible to examine internal consistency, construct validity, and criterion validity of the QUID. The proportion of UI types in diagnosed women in this sample closely corresponds to the proportion measured within large-scaled prevalence studies $[29,30]$ with a slight overemphasis of UUI. This speaks of the representativity of the following findings.

\section{Internal consistency}

The scores' distributions gave no indication of floor or ceiling effects. Both subscales of the QUID showed good 
internal consistency with Cronbach's alpha coefficients above the accepted standard of 0.7. This finding is confirmed by the strong correlations between the individual items of the QUID and their related subscale (item-totalcorrelations). The internal consistency is similar to that of the original English version: Cronbach's alpha is the same for the overall QUID (0.75), a little lower in the UUI-subscale (0.86 vs. 0.87 ), but clearly higher in the SUI-subscale (0.76 vs. 0.64) [5]. Cronbach's alpha was even higher in the Chinese (SUI: 0.91; UUI: 0.89) [10] and Spanish version (both subscales: 0.94) [9]. Item-totalcorrelations concerning the UUI-subscale were similar to those of the original English version [5]. Item-total-correlations concerning the SUI-subscale were higher than those in the original version with all correlation coefficients $>0.5$, which is considered as strong [24]. Altogether, reliability of the German-language QUID is good.

\section{Construct validity}

There was a weak correlation with the KHQ domain 'General health perception'. Between the SUI-subscale and 'General health perception' there even was no correlation. Since general health measures are not closely related to disease-specific measures [17], this discrepancy speaks of the discriminant validity of the QUID. Furthermore, there was no correlation between the SUI-subscale and the KHQ domain 'Sleep and energy disturbances'. This might be due to the fact that symptoms that disturb sleep, such as nocturia, are more likely to be found in UUI [2]. Because an overactive bladder syndrome is necessary for diagnosis of UUI [2], it is coherent that there was no correlation between the KHQ's OAB-domain and the SUI-subscale. The same applies to the non-existing correlation between the UUI-subscale and 'urine leakage at physical activity', because urine leakage at physical activity is a generic symptom of SUI [1-3]. The weak correlation between the QUID's subscales speaks of its ability to discriminate between SUI and MUI.

Evidence of convergent validity is provided by strong correlation of the QUID's UUI-subscale with the KHQ's OAB-domain as well as by the strong correlation of the QUID's SUI-subscale with the KHQ's item 'urine leakage at physical activity', which is characteristic of SUI [1-3]. QUID-KHQ-correlation has never been tested before. Hence a straight comparison with findings of further studies is not possible. However, score-correlations of the English-language QUID with corresponding items of the Urinary Distress Inventory (UDI), another commonly used UI-specific QoL-measure [31], were similar (both $0.68)[5]$.

\section{Criterion validity and diagnostic accuracy}

A first indication of the QUID's ability to discriminate between SUI and UUI is given by the mean scores of the UUI-subscale, which were significantly higher in women with UUI than in women without UUI. The same applies to the mean scores of the SUI-subscale and women with vs. without SUI. Concerning sensitivity both subscales were similar to the English-language version ( 0.83 vs. 0.85 for SUI and 0.83 vs. 0.79 for UUI) [4]. However, specificity ( 0.45 vs. 0.71 for SUI and 0.56 vs. 0.79 for UUI) and total hit ratio ( $73 \%$ vs. $80 \%$ ) were better in the English-language version [4]. This might be due to differences in the spectrum of disease between the studied populations which can result in a variation of sensitivity and/or specificity [8].

The ROC curves show that the given cut-off score $(\geq 6)$ leaded to an optimum in the UUI-subscale. In the SUIsubscale the given cut-off score $(\geq 4)$ did not lead to an optimum. Here the ROC curve has an optimum at a cutoff score of $\geq 6$. A cut-off score of $\geq 6$ in the SUI-subscale would enhance specificity to 0.64 but simultaneously would reduce sensitivity to 0.69 . Considering urogynecologic practice such an adjustment of the cut-off score cannot be recommended without reserve. Since all patients often benefit from initial treatment that is focused on UUI [2], some falsepositives in the UUI-subscale inherently are acceptable. The same applies to the SUI-subscale, because pelvic floor muscle training (PFMT), which is very-low risk, is the first choice therapy for SUI [1-3]. Therefore, it could be more important to gain sensitivity than specificity. The poorer performance of the ROC curve on the SUI-subscale could be due to the fact that the participants with SUI, according to the mean scores of the KHQ, had lower degrees of severity.

\section{Clinical implications and limitations}

The German-language QUID enables quick and simple assessment of SUI- and/or UUI-symptoms in German-speaking women. At this it is much more specific than pre-existing German-language UI-questionnaires like the KHQ which has a broader and more general perspective on UI-related symptoms and QoL [14]. Therefore, the QUID currently is the most qualified PROM which was psychometrically evaluated in the German-speaking area to assess SUI- and/ or UUI-symptoms. When used within respective clinical trials it focuses on SUI- and/or UUI-specific outcomes, while blinding out other dimensions [4]. Thus it brings out measurement results which are as precise as possible [32] and simultaneously are easy to interpret. The German-language QUID is also useful within urogynecologic practice as it gives a first impression of SUI- and/or UUI-symptoms in a standardized manner for the doctor but also for the patient. In particular it is suitable to assess symptom severity. It also 
can be used as a supportive tool to discriminate between SUI and UUI but positive results should be considered with caution, since specificity was not sufficient in both subscales.

Although this study created comprehensive knowledge about the psychometric properties of the German-language QUID, there were certain limitations. Since the online survey was performed anonymously, test-retest reliability could not be measured. Furthermore, sensitivity to change, which is the ability of an instrument to measure a change in condition, of the QUID was not assessed. This is due to the current coronavirus pandemic. To assess sensitivity of change study participants regularly obtain an intervention which is known as effective. Within the scope of UI this includes PFMT, bladder training (both professionally accompanied by a physical therapist), or surgical interventions (especially mid-urethral sling placement to treat SUI) [2]. Physiotherapy practices have been closed during coronavirus pandemic and many surgical interventions have been delayed to hold capacities for COVID-19-patients. However, sensitivity to change is indicated by strong correlations with related domains of the German-language KHQ, which already has shown its suitability both as research assessment and therapeutic monitoring tool by good sensitivity to change [17, 18]. Nevertheless, further research could provide evidence of the German-language QUIDs' sensitivity to change by applying it as outcome measure within an interventional study in the context of UI.

\section{Conclusions}

This evaluation of the German-language QUID in a sample of 161 women with UI indicated that its psychometric properties are good and, therefore, support its use both as basic diagnostic tool to distinguish between SUI, UUI, and MUI, and as patient-reported outcome measure in German-speaking populations. An examination of construct validity presented moderate to strong correlations with related domains of the KHQ. Both subscales of the German-language QUID had relatively high internal consistency. Additionally, it is able to provide an initial assessment of the type of UI. When distinguishing between SUI and UUI, however, the modest specificity should be taken into account.

\section{Appendix}

\section{See Table 5.}

Table 5 The German-language Questionnaire for Urinary Incontinence Diagnosis (QUID_German version)
Verlieren Sie Urin (auch nur wenige Tropfen) oder nässen Sie sich, Ihre Einlage oder Ihre Unterwäsche ein...

Do you leak urine (even small drops), wet yourself, or wet your pads or undergarments...

\begin{tabular}{|c|c|c|c|c|c|c|}
\hline & Nie & Selten & $\begin{array}{l}\text { Ab und } \\
\text { zu }\end{array}$ & Oft & Meistens & Immer \\
\hline & $\begin{array}{l}\text { None oft } \\
\text { he time }\end{array}$ & Rarely & $\begin{array}{l}\text { Once in } \\
\text { a while }\end{array}$ & Often & $\begin{array}{l}\text { Most of } \\
\text { the time }\end{array}$ & $\begin{array}{c}\text { All of the } \\
\text { time }\end{array}$ \\
\hline \multicolumn{7}{|l|}{$\begin{array}{l}\text {...wenn Sie husten oder niesen? } \\
\text {...when you cough or sneeze? }\end{array}$} \\
\hline \multicolumn{7}{|l|}{$\begin{array}{l}\text {...wenn Sie sich bücken oder etwas } \\
\text { hochheben? } \\
\text {...when you bend down or lift something } \\
\text { up? }\end{array}$} \\
\hline \multicolumn{7}{|l|}{$\begin{array}{l}\text {...wenn Sie schnell laufen, joggen oder } \\
\text { trainieren? } \\
\text {...when you walk quickly, jog or exercise? }\end{array}$} \\
\hline \multicolumn{7}{|l|}{$\begin{array}{l}\text {...wenn Sie sich entkleiden, um auf die } \\
\text { Toilette zu gehen? } \\
\text {...while you are undressing in ordert o use } \\
\text { the toilet? }\end{array}$} \\
\hline \multicolumn{7}{|l|}{$\begin{array}{l}\text { Müssen Sie so dringend urinieren, dass } \\
\text { Sie Urin verlieren (auch nur wenige } \\
\text { Tropfen) oder sich einnässen bevor Sie } \\
\text { die Toilette erreichen? } \\
\text { Do you get such a strong and } \\
\text { uncomfortable need to urinate that you } \\
\text { leak urine (even small drops) or wet } \\
\text { yourself before reaching the toilet? }\end{array}$} \\
\hline $\begin{array}{l}\text { Müssen Sie ins Badezimmer stürmen, } \\
\text { weil Sie so dringend urinieren müssen? } \\
\text { Do you have to rush tot he bathroom } \\
\text { because you get a sudden, strong need to } \\
\text { urinate? }\end{array}$ & & & & & & \\
\hline
\end{tabular}

Scoring: Each item scores 0 (None of the time), 1 (Rarely), 2 (Once in a while), 3 (Often), 4 (Most of the time) or 5 (All of the time). Responses for items 1,2, and 3 are summed for the SUI score. Responses for items 4,5 , and 6 are summed for the UUI score. Both scores have to be summed for the overall score 
Author contribution F Brandt: Project development, Data collection and analysis, Manuscript writing. E Solomayer: Manuscript writing and editing. P Sklavounos: Manuscript writing and editing.

Funding Open Access funding enabled and organized by Projekt DEAL.

Availability of data and material Not applicable.

Code availability Not applicable.

\section{Declarations}

Conflict of interest The authors declare that they have no conflict of interest.

Ethics approval This study is solely based on a survey. The Ethics Committee of the Medical Chamber of the Saarland (Saarbrücken, Germany) has confirmed that no ethical approval is required.

Consent to participate Informed consent was assumed by taking part and submitting the voluntary and anonymous online survey after completion.

Consent for publication Not applicable.

Open Access This article is licensed under a Creative Commons Attribution 4.0 International License, which permits use, sharing, adaptation, distribution and reproduction in any medium or format, as long as you give appropriate credit to the original author(s) and the source, provide a link to the Creative Commons licence, and indicate if changes were made. The images or other third party material in this article are included in the article's Creative Commons licence, unless indicated otherwise in a credit line to the material. If material is not included in the article's Creative Commons licence and your intended use is not permitted by statutory regulation or exceeds the permitted use, you will need to obtain permission directly from the copyright holder. To view a copy of this licence, visit http://creativecommons.org/licenses/by/4.0/.

\section{References}

1. Thüroff JW, Abrams P, Andersson KE, Artibani W, Chapple CL, Drake MJ, Hampel C, Neisius A, Schröder A, Tubaro A (2011) EAU guidelines on urinary incontinence. Eur Urol 59:387-400. https://doi.org/10.1016/j.eururo.2010.11.021

2. Aoki Y, Brown HW, Brubaker L, Cornu JN, Daly JO, Cartwright R (2017) Urinary incontinence in women. Nat Rev Dis Primers 3:17042. https://doi.org/10.1038/nrdp.2017.42

3. Shaban A, Drake MJ, Hashim H (2010) The medical management of urinary incontinence. Auton Neurosci 152:4-10. https://doi.org/ 10.1016/j.autneu.2009.09.022

4. Bradley CS, Rovner ES, Morgan MA, Berlin M, Novi JM, Shea JA, Arya LA (2005) A new questionnaire for urinary incontinence diagnosis in women: development and testing. Am J Obstet Gynecol 192:66-73. https://doi.org/10.1016/j.ajog.2004.07.037

5. Bradley CS, Rahn DD, Nygaard IE, Barber MD, Nager CW, Kenton KS, Siddiqui NY, Abel RB, Spino C, Richter HE (2010) The Questionnaire for Urinary Incontinence Diagnosis (QUID): validity and responsiveness to change in women undergoing nonsurgical therapies for treatment of stress predominant urinary incontinence. Neurourol Urodyn 29:727-734. https://doi.org/10. 1002/nau.20818

6. Farrell SA, Bent A, Amir-Khalkhali B, Rittenberg D, Zilbert A, Farrell KD, O'Connell C, Fanning C (2013) Women's ability to assess their urinary incontinence type using the QUID as an educational tool. Int Urogynecol J 24:759-762. https://doi.org/10. 1007/s00192-012-1925-6

7. Nunnally JC, Bernstein IH (1994) Psychometric theory, 3rd edn. McGraw-Hill, New York

8. Šimundić AM (2009) Measures of diagnostic accuracy: basic definitions. EJIFCC 19:203-211

9. Treszezamsky AD, Karp D, Dick-Biascoechea M, Ehsani N, Dancz C, Montoya TI, Olivera CK, Smith AL, Cardenas R, Fashokun T, Bradley CS (2013) Spanish translation and validation of four short pelvic floor disorders questionnaires. Int Urogynecol J 24:655-670. https://doi.org/10.1007/ s00192-012-1894-9

10. Li CY, Zhu L, Lang JH, Xu T, Shi XW (2016) Exploratory and confirmatory factor analyses for testing validity and reliability of the Chinese language questionnaire for urinary incontinence diagnosis. Zhonghua Fu Chan Ke Za Zhi 51:357-360. https://doi. org/10.3760/cma.j.issn.0529-567X.2016.05.007

11. Srisukho S, Phongnarisorn C, Morakote N (2018) Validation of the questionnaire for urinary incontinence diagnosis-Thai version [QUID-Thai version]. J Med Assoc Thai 101:1251-1254

12. Mokhlesi SS, Kariman N, Ebadi A, Khoshejad F, Dabiri F (2017) Psychometric properties of the questionnaire for urinary incontinence diagnosis of married women of Qom City 2015. J Rafsanjan Univ Med Sci 15:955-966

13. Wild D, Grove A, Martin M, Eremenco S, McElroy S, VerjeeLorenz A, Erikson P (2005) Principles of good practice for the translation and cultural adaption process for patient-reported outcomes (PRO) measures: report of the ISPOR task force for translation and cultural adaption. Value Health 8:94-104. https:// doi.org/10.1111/j.1524-4733.2005.04054.x

14. Kelleher CJ, Cardozo LD, Khullar V, Salvatore S (1997) A new questionnaire to assess the quality of life of urinary incontinent women. Br J Obstet Gynaecol 104:1374-1379. https://doi.org/10. 1111/j.1471-0528.1997.tb11006.x

15. Conway K, Uzun V, Marrel A, Cordozo L, Kelleher CJ, Haye I (1997) Linguistic validation of the King's Health Questionnaire (KHQ) in eight languages (abstract). Value Health 2:204. https:// doi.org/10.1016/S1098-3015(11)71018-X

16. Reese PR, Pleil AM, Okano GJ, Kelleher CJ (2003) Multinational study of reliability and validity of the King's Health Questionnaire in patients with overactive bladder. Qual Life Res 12:427-442. https://doi.org/10.1023/a:1023422208910

17. Bjelic-Radisic V, Dorfer M, Tamussino K, Greimel E (2005) Psychometric properties and validation of the German-language King's Health Questionnaire in Women with stress urinary incontinence. Neurourol Urodyn 24:63-68. https://doi.org/10.1002/nau. 20092

18. Bjelic-Radisic V, Dorfer M, Tamussino K, Daghofer F, Kern P, Frudinger A, Greimel E (2005) The King's health questionnaire for assessing quality of life in women with urinary incontinence (German version). Geburtsh Frauenheilk 65:1042-1050. https:// doi.org/10.1055/s-2005-872957

19. Donovan JL, Badia X, Corcos J et al (2002) Symptom and quality of life assessment. In: Abrams P, Cardozo L, Khoury S, Wein A (eds) Incontinence. Health Publication Ltd, Plymouth, pp 267-316

20. Hebbar S, Pandey H, Chawla A (2015) Understanding King's health questionnaire (KHQ) in assessment of female urinary incontinence. Int J Res Med Sci 3:531-538. https://doi.org/10. 5455/2320-6012.ijrms20150301 
21. Kruskal WH, Wallis WA (1952) Use of ranks in one-criterion variance analysis. J Am Stat Assoc 47:583-621. https://doi.org/ 10.1080/01621459.1952.10483441

22. Mann HB, Whitney DR (1947) On a test of whether one of two random variables is stochastically larger than the other. Ann Math Statist 18:50-60. https://doi.org/10.1214/aoms/1177730491

23. Cortina JM (1993) What is coefficient alpha? An examination of theory and applications. J Appl Psychol 78:98-104. https://doi. org/10.1037/0021-9010.78.1.98

24. Cohen J (1988) Statistical power analysis for the behavioral sciences, 2nd edn. Lawrence Erlbaum Associates, New York

25. Zou KH, O’Malley AJ, Mauri L (2007) Receiver-operating characteristic analysis for evaluating diagnostic tests and predictive models. Circulation 115:654-657. https://doi.org/10.1161/CIRCU LATIONAHA.105.594929

26. Youden WJ (1950) Index for rating diagnostic tests. Cancer 3:3235. https://doi.org/10.1002/1097-0142(1950)3:1\%3c32::aid-cncr2 820030106\%3e3.0.co;2-3

27. Faul F, Erdfelder E, Lang AG, Buchner A (2007) G*Power 3: a flexible statistical power analysis program for the social, behavioral, and biomedical sciences. Behav Res Methods 39:175-191. https://doi.org/10.3758/bf03193146
28. Shapiro SS, Wilk MB (1965) An analysis of variance test for normality (complete samples). Biometrika 52:591-611. https:// doi.org/10.1093/biomet/52.3-4.591

29. Hannestad YS, Rortveit G, Sandvik H, Hunskaar S (2000) A community-based epidemiological survey of female urinary incontinence: the Norwegian EPINCONT study. J Clin Epidemiol 53:1150-1157. https://doi.org/10.1016/s0895-4356(00)00232-8

30. Ebbesen MH, Hunskaar S, Rortveit G, Hannestad YS (2013) Prevalence, incidence and remission of urinary incontinence in women: longitudinal data from the Norwegian HUNT study (EPINCONT). BMC Urol 13:27. https://doi.org/10.1186/ 1471-2490-13-27

31. Shumaker SA, Wyman JF, Uebersax JS, McClish D, Fantl JA (1994) Health-related quality of life measures for women with urinary incontinence: the incontinence impact questionnaire and urogenital distress inventory. Qual Life Res 3:291-306. https:// doi.org/10.1007/BF00451721

32. Hays R (2005) Generic versus disease-targeted instruments. In: Fayers P, Hays R (eds) Assessing quality of life in clinical trials, 2nd edn. Oxford University Press, Oxford, pp 3-8

Publisher's Note Springer Nature remains neutral with regard to jurisdictional claims in published maps and institutional affiliations. 